\title{
FX EVENT ORgANIZATION
}

\author{
${ }^{1}$ Muthu Krishnan.S and ${ }^{2}$ Angelin Ranjithamani.D ${ }^{3}$ Deepa.C \\ ${ }^{1}$ Department of Computer Application, Francis Xavier Engineering College. \\ ${ }^{2}$ HOD,Department of Computer Application, Francis Xavier Engineering \\ College.
}

${ }^{3}$ Department of Computer Application, Francis Xavier Engineering College.

\begin{abstract}
Online event management system is an online event management system software project that serves the functionality of an event manager. The system allows registered user login and new users are allowed to register on the application. The system helps in the management of events, users and the aspects related to them. This proposed to be a web application. The project provides most of the basic functionality required for an event type e.g. [technical,Non-technical events,etc]. College students are advanced in thinking, who are senior and specialized professionals trained by the nation. They have independent thinking skills, and often have unique views and opinions on events. In this paper, an index is constructed to solve the difficulty of monitoring the ideological dynamics of college students, since the ideological dynamics of college students is difficulty to be captured. In particular, a visualization management information system is developed to monitor the ideological dynamics of college students based on big data. This system is based on the B/S architecture, which uses the SQL Server database. This system realizes the functions of index modification, document entry, word segmentation statistics, index correlation, keyword search, index analysis, document analysis.
\end{abstract}

\section{KEYWORDS}

Events and Registration.

\section{INTRODUCTION}

Event management is Traditional education is defined as teacher-centered delivery of instruction to classes of students who are the receivers of information. Traditional institutions generally stress basic educational practices and expect mastery of academic learning in the core subjects. Most organizations generally follow this educational model[8]. On the other hand, an online educational or e-learning service is a website, which teaches and helps students improve in certain subjects[5]. These are normally, used by institutes to let students learn from home and complete online homework.

Traditional education is not necessarily the most effective way of learning, because no student can pay full of attention to the class lectures, and it cannot be possible for a student to attend the class regularly. So due to many reasons such as lack of concentration, absent to the class ,wrong understanding of the concept,etc.,the education system may face a poor outcome.Another factor is that,a lecture rmay not handle an efficient teaching methodology. E-learning as a method of education makes the learners undergo contemplation, remoteness, as well as lack of interaction or relation. It therefore requires a very strong inspiration as well as skills with to the management 
of time in order to reduce such effects. With respect to clarifications, offer of explanations, as well as interpretations, the e-learning method might be less effective that the traditional method of learning. The learning process is much easier with the use of the face to face encounter with the instructors or teachers[2].

Both traditional and e-learning system has its own advantages and disadvantages. In order to overcome the disadvantages, the project propose an idea of converting the education system into active learning education, by sharing the videos of class lectures through online. This method will deliver the benefits of both traditional and e-learning system and makes the education more efficient.

\section{Problem Statement}

The Online Event System in JSP has become a fast growing event method because of its speed and accuracy. It also needed less manpower to execute the event. Almost all organizations nowa-days, are conducting their objective events by online event system.

Online event systems save the events information in a database Staff can add/delete events

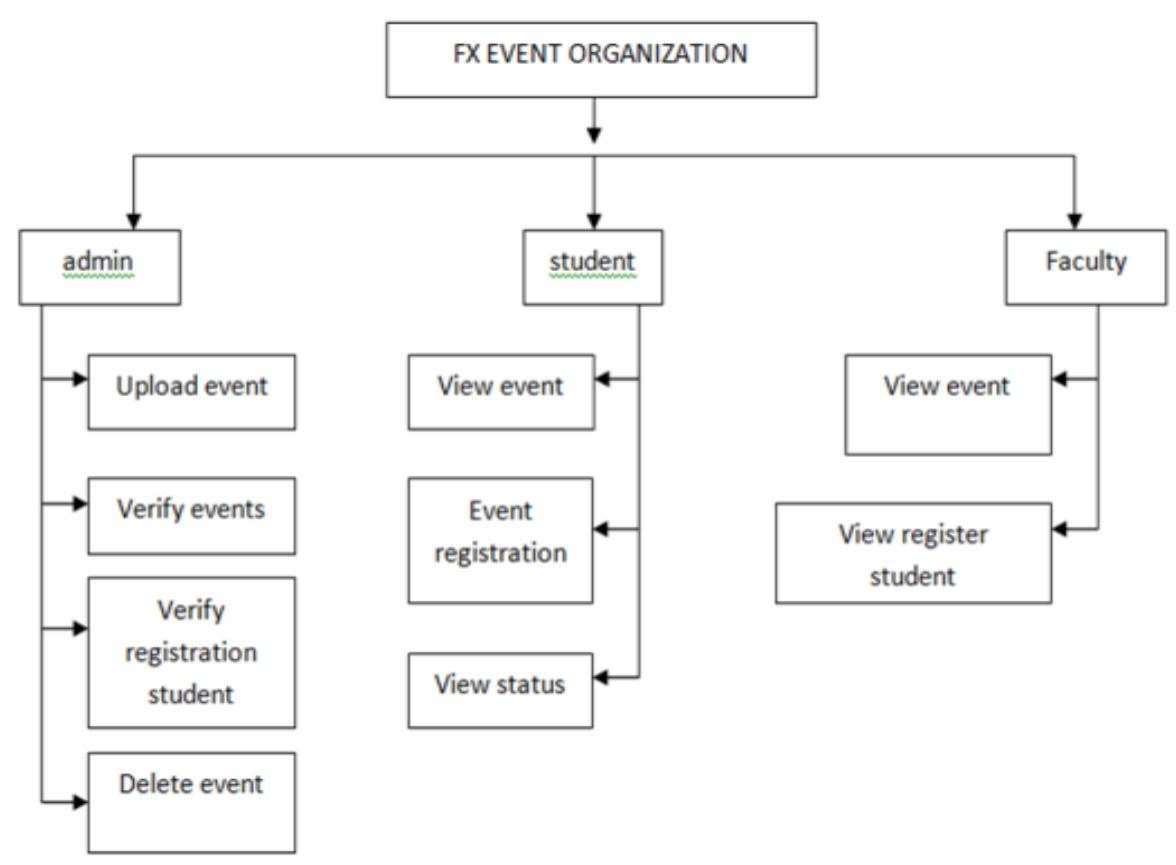

Figure: 1 Architecture Diagram

\section{EXPERIMENT AND RESULTS}

\section{Admin}

Online Event System is a web based application to conduct events online. In these modules we can add program schedules and store data. 


\title{
Conduct Event
}

In this module the institution can add programs. They can also set time for each event according to the schedule allocation. They can add any type of events like technical events, non-technical events.

\section{Add or Delete Events}

Events can be added or deleted only by the admin.

\section{Database Collections}

User requirements are inserted on the database and it will be retrieved by the event management system .When the student finishes their work, they will update the requirements via pictures which were taken by them. User requirements are inserted on database and it will be retrieved by admin and student module. The all records will be stored in the database.

\begin{abstract}
About Project
This project consists of two main modules Admin and Student. In the Admin module we have the login page which is used to login for their Admin and if new users can register themselves and then login. The Admin can add their own students with their category. They can also add events for particular technical events. The questions can be randomly given to the students by selecting randomizer on. .
\end{abstract}

While login as a student the student can take the events posted by their Admin.

\section{Output Screen}

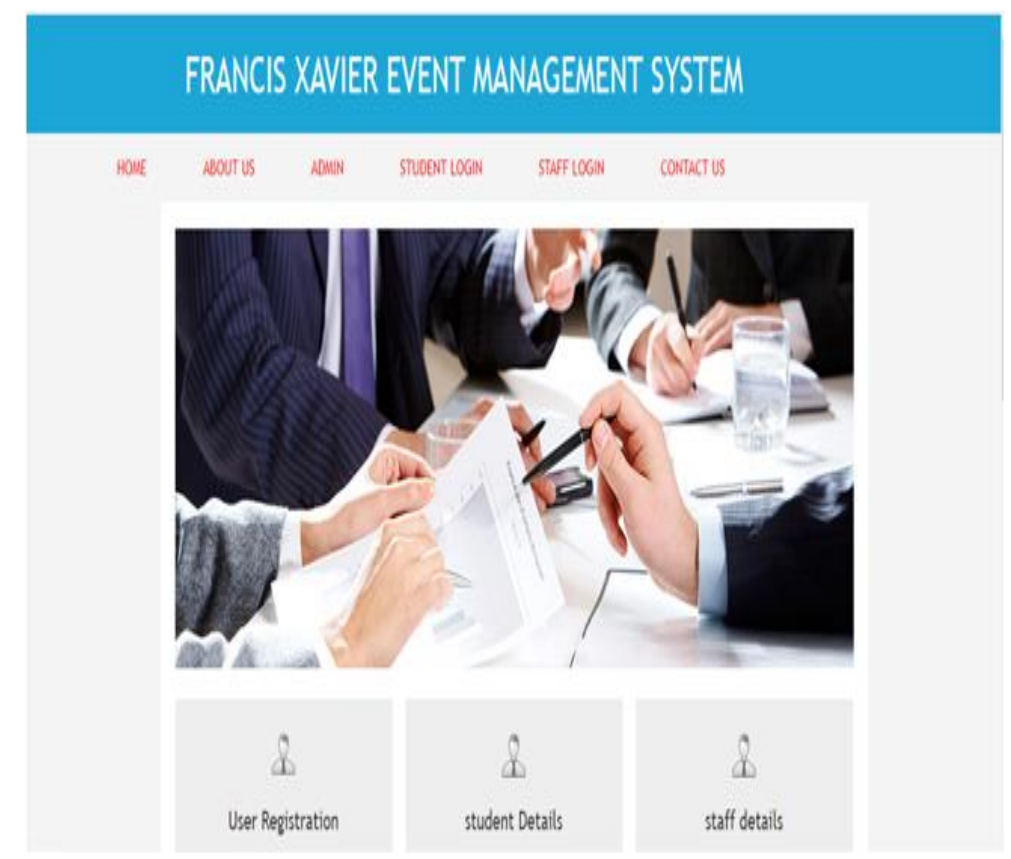

Figure: 1 DashBoard 


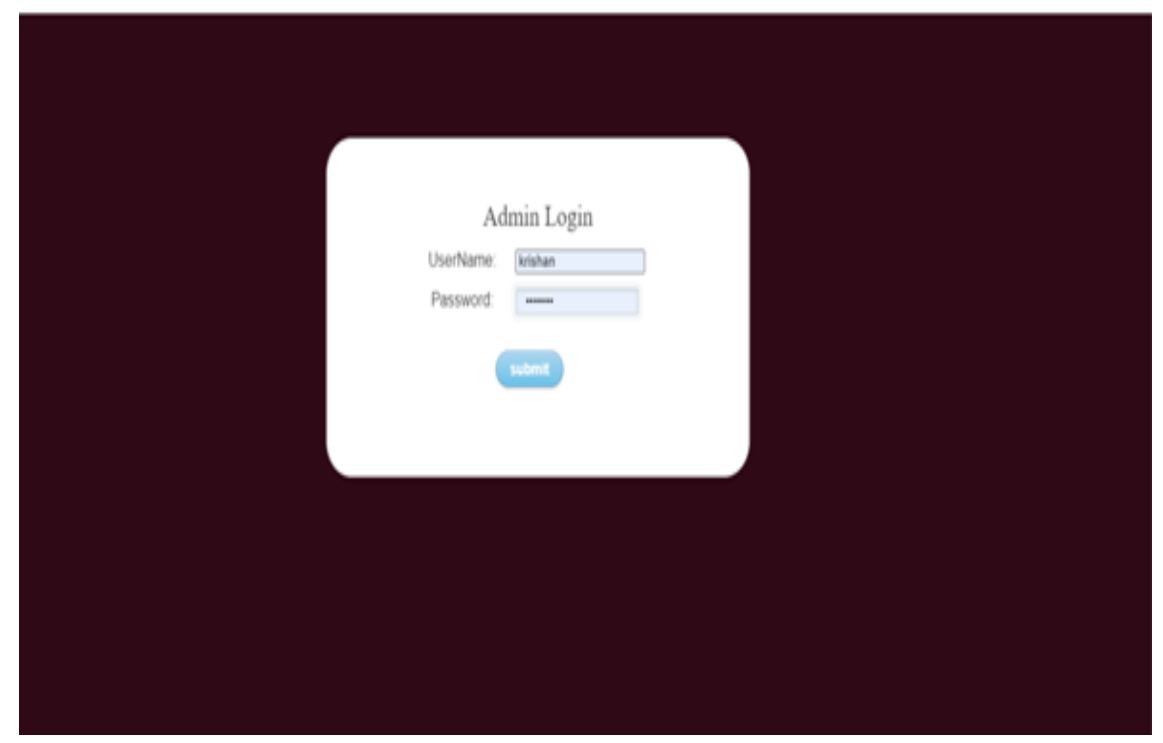

Figure: 2 Register and Login Page

\section{Choose Your Requirement Links Here}

$$
\begin{aligned}
& \text { Student's Registration Form } \\
& \text { Staff's Registration Form } \\
& \text { User Revocation Form } \\
& \text { Go to Home Page }
\end{aligned}
$$

Figure: 3 Choose Requirements link 


\section{File Upload Page}

welcome, kicha

Select a File: Choces fin no no the dous

Exit

Figure: 4 Upload File

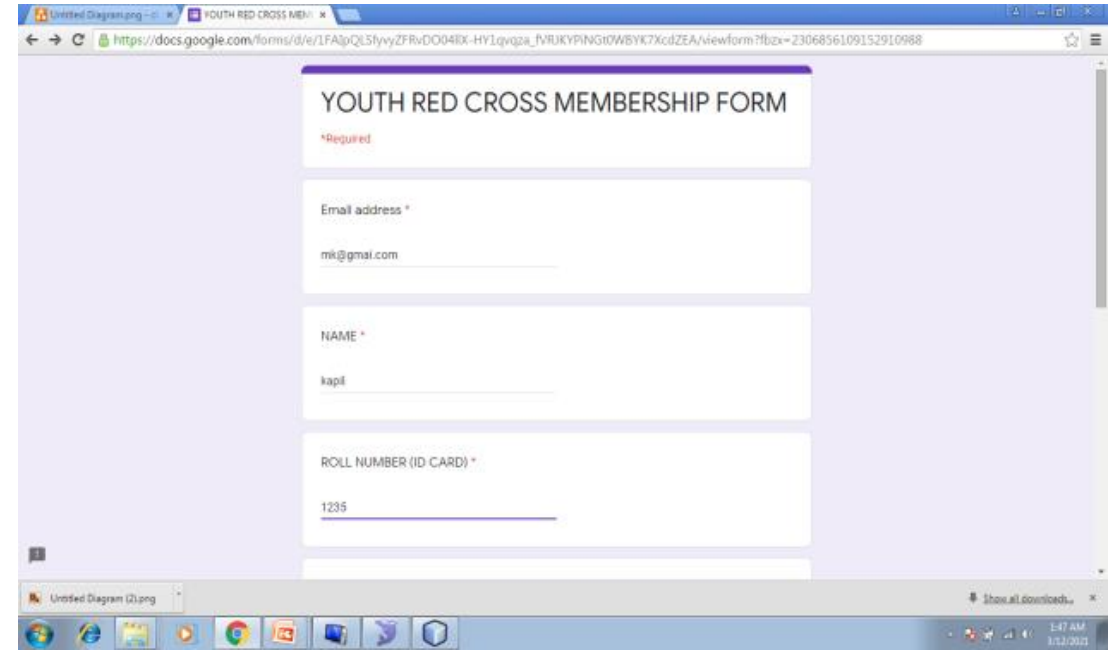

Figure: 5 Club Register

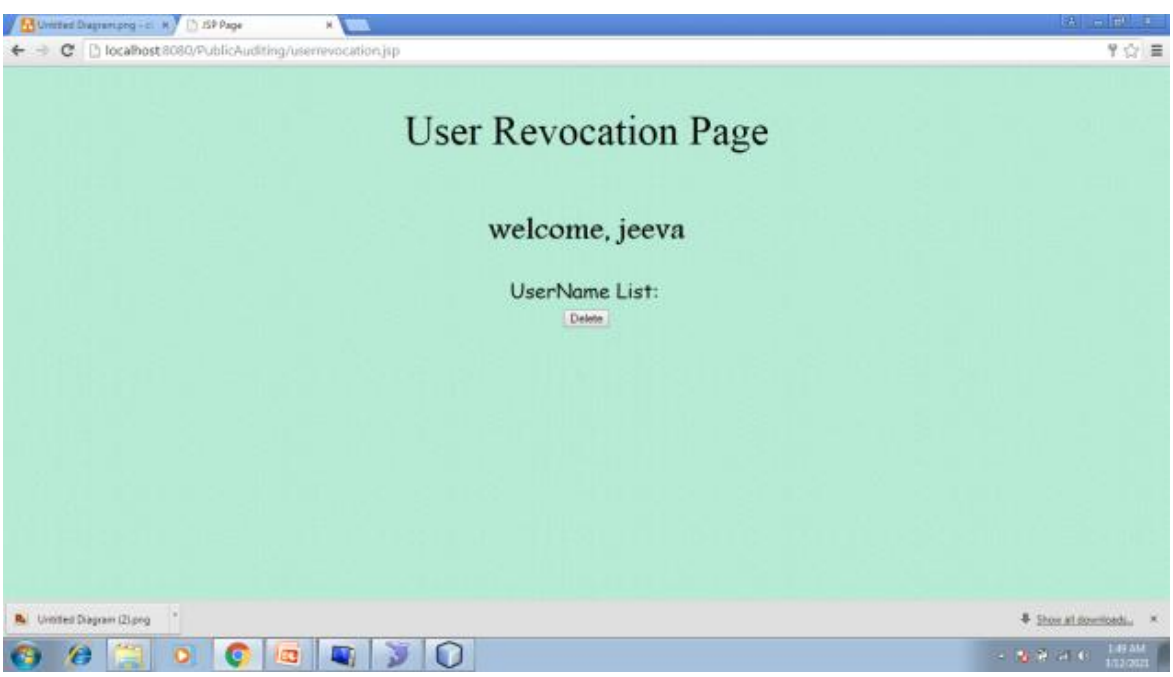

Figure:6 User Revocation 


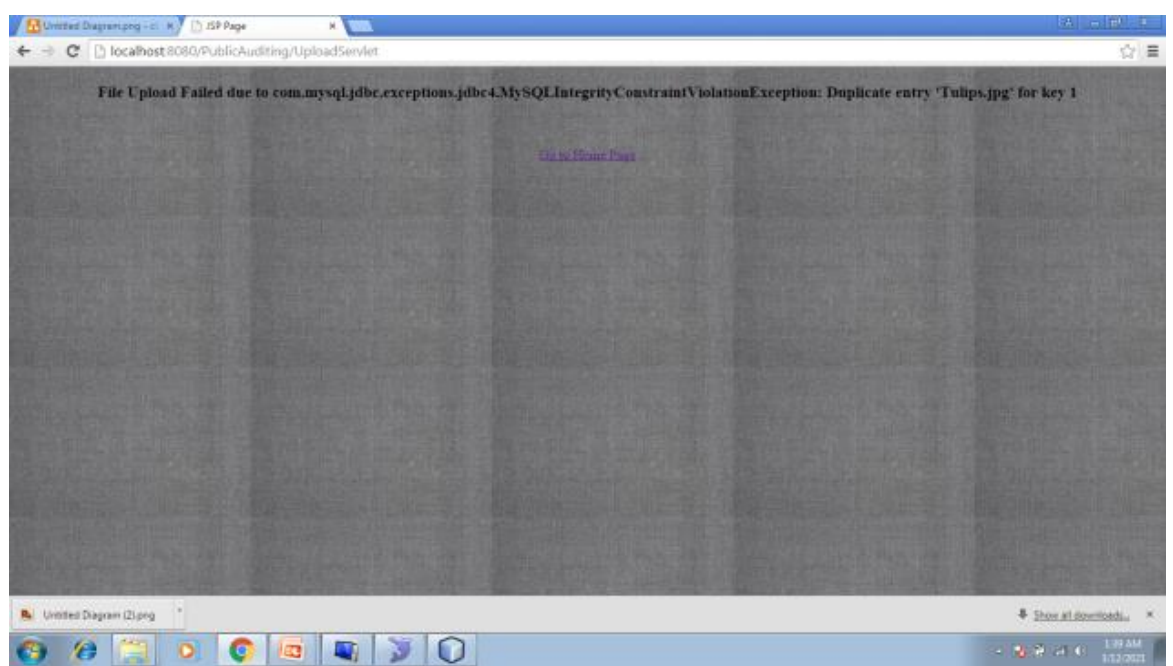

Figure:7 Faculty File Upload

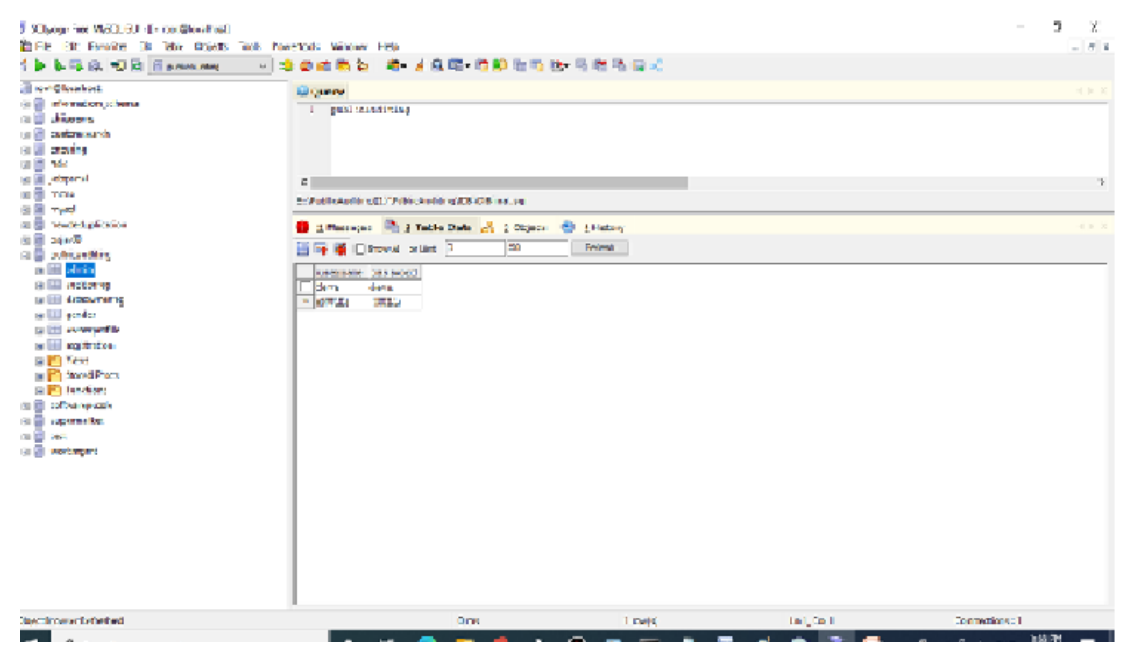

Figure:8 MySql Data Server

\section{Performance Analysis}

The existing and proposed systems are analyzed. The problems can be easily rectified with this concept. Nearly $70 \%$ of the performance has been increased.

\section{CONCLuSiON}

We have prepared a new system after identifying issues in the existing manual system. Participant students can view and register for events online. The record maintenance use of previous records becomes easy and to join the event. Thus we will implement a College Event Organizer system to address the problem faced by event organizers with respect to communication and working methods. 


\section{FUTURE ENHANCEMENT}

We would like to propose two different works: First we would like to see improvement of the platform to look more interactive with motivate the user and engage to join the club activities. Second we would like to add interactive and gaming club activity, to engage the user in the event .To join the club in more interact to in gaming features will be added. The future security issues, security can be improved using emerging technologies.

\section{REFERENCES}

1) Manuel Mazzara, Luca Biselli, Pier Paolo Greco, Nicola Dragoni, Antonio Marraffa, Nafees Qamar, and Simona de Nicola. Social networks and collective intelligence: a return to the agora. IGI Global, 2013.

2) Andrei Lebedev, JooYoung Lee, V'ictor Rivera, and Manuel Mazzara. Link prediction using top-k shortest distances. In Data Analytics - 31st British International Conference on Databases, BICOD 2017, London, UK, July 10-12, 2017, Proceedings, pages 101-105, 2017.

3) Liu Qingzao. Practical Management of Sport Events. People's Education Press, 2006(in Chinese)

4) IOC Manual for candidate cities for the games of the XXIX Olympiad 2008[Z]. Lausanne: International Olympic Committee, 2000

5) Glenn Bowdin, Johnny Allen, William O’Toole, Rob Harris, Ian McDonnell, Events Management, Routledge London and New York 2011.

6) Oliver Thomas, Bettina Hermes, Peter Loos, "Reference modelbased event management," International Journal of Event Management Research, Volume 4, Number 1, 2008.

7) Xu Chunjiao, Chu Dianhui, Li Chunshan, "City Event Management System Based on Multiple Data Source", International Conference on Service Science (ICSS), 2015.

8) Masayuki Otani, Toru Ishida, Yohei Murakami, Takao Nakaguchi,"Event management for simultaneous actions in the Internet of Things", IEEE 3rd World Forum on Internet of Things (WFIoT), 2016. 


\section{AUTHORS}

Mr.S.Muthu Krishnan doing final year MCA in Francis Xavier Engineering College.

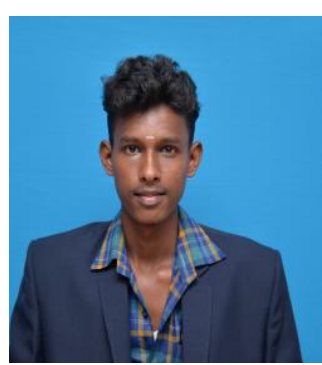

Mrs. D. Angeline Ranjithamani is working as Assistant Professor and HOD in the Department of Computer Applications, Francis Xavier Engineering College. She is having teaching experience of $12+$ years. Her area of interest is Wireless Sensor networks.

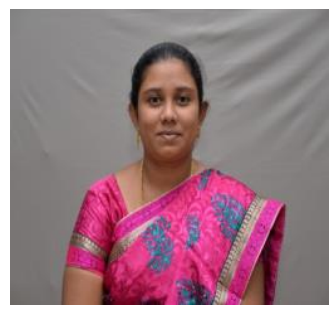

Ms.C.Deepa doing first year MCA in Francis Xavier Engineering College.

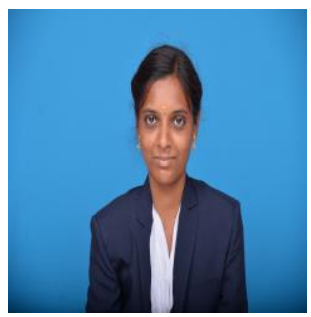

